\title{
Phosphatidylinositol 3-Kinase Regulatory Subunit Beta
}

National Cancer Institute

\section{Source}

National Cancer Institute. Phosphatidylinositol 3-Kinase Regulatory Subunit Beta. NCI

Thesaurus. Code C101285.

Phosphatidylinositol 3-kinase regulatory subunit beta (728 aa, $\sim 82 \mathrm{kDa}$ ) is encoded by the human PIK3R2 gene. This protein is involved in the modulation of both tyrosine phosphorylation and signal transduction. 